\title{
Visual laterality in dolphins: importance of the familiarity of stimuli
}

\author{
Catherine Blois-Heulin ${ }^{*}$, Mélodie Crével ${ }^{1}$, Martin Böye ${ }^{2}$ and Alban Lemasson ${ }^{1}$
}

\begin{abstract}
Background: Many studies of cerebral asymmetries in different species lead, on the one hand, to a better understanding of the functions of each cerebral hemisphere and, on the other hand, to develop an evolutionary history of hemispheric laterality. Our animal model is particularly interesting because of its original evolutionary path, i.e. return to aquatic life after a terrestrial phase. The rare reports concerning visual laterality of marine mammals investigated mainly discrimination processes. As dolphins are migrant species they are confronted to a changing environment. Being able to categorize new versus familiar objects would allow dolphins a rapid adaptation to novel environments. Visual laterality could be a prerequisite to this adaptability. To date, no study, to our knowledge, has analyzed the environmental factors that could influence their visual laterality.

Results: We investigated visual laterality expressed spontaneously at the water surface by a group of five common bottlenose dolphins (Tursiops truncatus) in response to various stimuli. The stimuli presented ranged from very familiar objects (known and manipulated previously) to familiar objects (known but never manipulated) to unfamiliar objects (unknown, never seen previously). At the group level, dolphins used their left eye to observe very familiar objects and their right eye to observe unfamiliar objects. However, eyes are used indifferently to observe familiar objects with intermediate valence.

Conclusion: Our results suggest different visual cerebral processes based either on the global shape of well-known objects or on local details of unknown objects. Moreover, the manipulation of an object appears necessary for these dolphins to construct a global representation of an object enabling its immediate categorization for subsequent use. Our experimental results pointed out some cognitive capacities of dolphins which might be crucial for their wild life given their fission-fusion social system and migratory behaviour.
\end{abstract}

\section{Background}

Laterality, previously considered to be exclusively a human characteristic, has been show in many vertebrates as well as invertebrate species (for example: [1-6]). Thus, the asymmetry of cerebral functions seems to be the rule rather than the exception in the animal kingdom [7]. Analyses of lateralized motor, perceptual or behavioral responses broaden our understanding of cerebral organization and of treatment of information by each cerebral hemisphere.

Characteristics of perceived stimuli can be linked to the treatment of the information received by one of the cerebral hemispheres and to the implication of a given

\footnotetext{
* Correspondence: catherine.blois-heulin@univ-rennes1.fr

'UMR 6552 University of Rennes 1 - CNRS, Station Biologique, 35380

Paimpont, France

Full list of author information is available at the end of the article
}

hemisphere. This link is modulated by subjects' internal state such as levels of hunger, vigilance or stress [8], as well as their age [9] or social environment [10]. Moreover, stimulus characteristics like emotional value $[11,12]$ and novelty $[13,14]$ are known to influence perceptual laterality.

The anatomical characteristics of the visual nervous system make visual laterality a good candidate to study perceptual laterality, and most particularly in dolphins. It is well known that the two cerebral hemispheres do not receive sensory information from a single stimulus in the same proportions. For instance in many mammals, the contralateral hemisphere receives monocular visual information faster (crossed fibers) than that received by the ipsilateral hemisphere (uncrossed fibers) $[8,15]$. So the involvement of each cerebral hemisphere depends on the organization, the quantity and the transmission speed of
C Biomed Central

(c) 2012 Blois-Heulin et al; licensee BioMed Central Ltd. This is an Open Access article distributed under the terms of the Creative Commons Attribution License (http://creativecommons.org/licenses/by/2.0), which permits unrestricted use, distribution, and reproduction in any medium, provided the original work is properly cited. 
nervous impulses [15]. Dolphins are particularly interesting model for hemispheric laterality investigations for at least four reasons. First, their eyes are situated laterally and all their optic fibers cross $[16,17]$ allowing a reliable interpretation of the underlying cerebral asymmetry. The left hemisphere receives visual information exclusively from the right eye, and the right hemisphere from the left eye. Moreover, stronger isolation of brain hemispheres is due to relatively less developed corpus callosum [18]. Preferential use of a given eye (also called eye use bias) at the group level indicates the treatment of visual information by the contralateral hemisphere $[11,19]$. Second, several reports evidence the existence of lateralized behavior in marine mammals (whales: [20,21]; dolphins: [16,22-25]). For example, the general tendency of dolphins to swim counter-clockwise $[16,24,25]$ might indicate the presence of laterality in this species. Third, previous reports indicated that dolphins generally use monocular vision (due to a narrow binocular visual field), and that they visually solve visio-spatial tasks better using their right eye and therefore their left brain hemisphere [17,24,26-29]. However, a recent study has shown that even if dolphins were clearly able to visually discriminate between familiar and unfamiliar human beings, they preferentially used their left eye to look at those two categories of people [30]. Forth, dolphins possess a high brain/body ratio [31], and several of the brain's morphological traits differ from those of terrestrial mammals [31-34]: their brains present anatomical structures similar to those of highly evolved brains, but at the same time, the organization of their rudimentary neocortex recalls more that of the hypothetical ancestor of mammals [35]. Analysis of their perceptual laterality should help understand the implication of each hemisphere in the treatment of various types of information, compared to other species.

One of the most frequently studied characteristics of stimuli influencing perceptual laterality is novelty). A certain consensus appears concerning the processing of the novelty of a stimulus ('Novelty hypotheses'). Generally, the left eye is privileged to look at novel stimuli (chicks: [36-38], fish: $[39,40])$ and/or to be better at processing or storing visual information which allows recognition of individual conspecific $[41,42]$. But exceptions can be found. De Boyer Des Roches et al [43] have shown that mares used preferentially their right eye to explore novel objects. According to Navon [44,45], characteristics of objects can be visually analyzed either globally or in detail (local traits). Local characteristics are mainly analyzed by the posterior superior temporal-parietal regions of the left hemisphere while global characteristics are analyzed by the posterior superior temporal-parietal regions of the right hemisphere ('Information treatment modality hypotheses') [46-51]. Thus, a link between the type of information treatment and the stimulus characteristics can be surmised: global analysis should be favored when observing a familiar object, whereas local analysis should occur in presence of a novel object to gather detailed information.

Our aim was to understand how these marine mammals perceive, analyze and treat visual stimuli with different levels of familiarity (i.e. unfamiliar, familiar nonmanipulated, very familiar manipulated). In this study the following questions were investigated experimentally: (1) Is there a behavioral laterality in dolphins, as it was found in others marine animals? (2) How does stimulus novelty affect the visual preference in dolphins? Three contradictory predictions can be done. First, based on the 'novelty hypotheses', dolphins should preferentially use their left eye to look at novel objects (unfamiliar) and should not display any preference for non-novel objects (familiar and very familiar). Second, according to the 'Information treatment modality hypothesis' [44,45], dolphins should use their left eye to look at very familiar objects, because a global visual inspection is sufficient to recognize and categorize the stimulus, but use their right eye to look at unfamiliar objects for which a more detailed visual inspection is required. The third prediction was based on Thieltges et al [30] results. These authors have demonstrated that dolphins used their left eye to look at human whatever their degree of novelty. So we wondered whether dolphins would generalize this left eye preference to look at all kinds of objects, regardless of their degree of novelty. 3) Is there a link between visual and swimming laterality? As swimming laterality seems strong in captive dolphins, we also analyzed the swimming preferences of our animals in order to control that the visual laterality observed was not a direct consequence of swimming preferences.

\section{Results}

\section{Reactivity}

Stimulus category neither influenced the number of trials when dolphins approached and observed the set-up spontaneously (Friedman test, $\mathrm{df}=2, \chi^{2}=6.35, \mathrm{p}=0.096$ ), nor the total number of gazes at objects of each category significantly (Friedman test, $\mathrm{df}=2, \chi^{2}=5.08, \mathrm{p}=0.166$ ). Dolphins preferred monocular to binocular vision to look at object of all categories (Wilcoxon tests, $\mathrm{z}=2.02$, $\mathrm{p}=0.043)$.

\section{Laterality \\ First reaction (Table 1)}

Three dolphins (Cecil, Peos and Thea) used their left eye to observe very familiar previously manipulated objects, whereas two dolphins (Cecil and Mininos) used their left eye to observe familiar never-manipulated objects. None of the dolphins was lateralized when viewing unfamiliar objects (Table 1). 
Table 1 Variation of the laterality index (IVL) according the level of object familiarity for the first reaction, p: binomial test, bold character: significant results, $p<0.05$, L: left eye used

CECIL PEOS MININOS THEA AMTAN

\begin{tabular}{cccccc}
\hline Familiar-Manipulated & & & & & \\
VLI & $\mathbf{- 0 . 8 8}$ & $\mathbf{- 0 . 5 8}$ & -0.29 & $\mathbf{- 0 . 6 3}$ & -0.29 \\
P & $\mathbf{0 . 0 0 1}$ & $\mathbf{0 . 0 1 9}$ & $\mathbf{0 . 4 2 4}$ & $\mathbf{0 . 0 2 1}$ & 0.332 \\
Bais & L & $\mathbf{L}$ & $\mathrm{ns}$ & $\mathbf{L}$ & $\mathrm{ns}$ \\
\hline $\begin{array}{c}\text { Familiars-Never } \\
\text { Manipulated }\end{array}$ & & & & & \\
VLI & $\mathbf{- 0 . 5 6}$ & -0.47 & $\mathbf{- 0 . 8 3}$ & 0.07 & 0.06 \\
P & $\mathbf{0 . 0 3 1}$ & 0.118 & $\mathbf{0 . 0 0 6}$ & 1.000 & 1.000 \\
Bais & $\mathrm{L}$ & $\mathrm{ns}$ & $\mathbf{L}$ & $\mathrm{ns}$ & $\mathrm{ns}$ \\
\hline Unfamiliar & & & & & \\
VLI & 0.29 & 0.18 & 0.37 & 0.43 & 0.33 \\
P & 0.424 & 0.629 & 0.167 & 0.180 & 0.238 \\
Bais & $\mathrm{ns}$ & $\mathrm{ns}$ & $\mathrm{ns}$ & $\mathrm{ns}$ & $\mathrm{ns}$ \\
\hline
\end{tabular}

At the group level, a significant left bias was evident when watching at very familiar previously manipulated objects ( $\mathrm{t}$ test, $\mathrm{t}=-4.80, d f=4, \mathrm{p}=0.009$ ) (Figure $1 \mathrm{~A}$ ). Conversely, a significant right bias was evidenced for watching at unfamiliar objects $(t$ test, $\mathrm{t}=7.50, d f=4$, $\mathrm{p}=0.002)$. When watching at familiar never manipulated, objects the dolphins did not use one eye preferably ( $t$ test, $\mathrm{t}=-1.95, d f=4, \mathrm{p}=0.123$ ) (Figure $1 \mathrm{~A}$ ).

Strength of laterality did not vary significantly with experimental situation (Friedman test, ABS(VLI), $\chi^{2}=$ 1.20, $d f=2, \mathrm{p}=0.55)$.

\section{Reactions following the first reaction}

Peos, Mininos and Thea used more their left eye to look at very familiar, previously manipulated, objects. Two dolphins (Cecil and Peos) used their left eye significantly more frequently to look at familiar never manipulated objects. Conversely, Amtan used more her right eye to observe unfamiliar objects (Table 2).

At the group level, as for the first reaction, a significant left bias was evidenced for watching at very familiar previously manipulated objects $(t$ test, $\mathrm{t}=-3.41, d f=4, \mathrm{p}=$ 0.027 ), but no significant bias was found for watching at familiar never manipulated objects ( $t$ test, $d f=4, \mathrm{t}=$ $-1.91, \mathrm{p}=0.129$ ). The following reactions to unfamiliar objects differed significantly from the first reaction to these objects as no bias towards the usage of the left or right eye was found ( $t$ test, $d f=4, \mathrm{t}=0.23, \mathrm{p}=0.832$ ) (Figure 1B).

Strength of laterality did not vary significantly between the three experimental situations (Friedman test, $\chi^{2}=$ 0.89, $d f=3, \mathrm{p}=0.85$ ).

Comparisons of bias and strength of laterality between the first and the following reactions

Laterality indices and strength of laterality did not differ significantly between the first and the following reactions irrespective of the experimental situation (Wilcoxon test, $\mathrm{n}=5$, FM situation: VLI $\mathrm{z}=0.13 \mathrm{p}=0.893$, Abs (VLI) $\mathrm{z}=0.13 \mathrm{p}=0.893$; FNM situations: VLI $\mathrm{z}=$ $0.40 \mathrm{p}=0.686$, Abs (VLI) $\mathrm{z}=0.40 \mathrm{p}=0.686$; NF condition: VLI z $=1.21 \mathrm{p}=0.225$, Abs (VLI) $\mathrm{z}=0.40 \mathrm{p}=$ 0.686).

\section{Rotational bias}

All our dolphins were strongly lateralized, they swam significantly more frequently in one direction than without direction (binomial test: lateralized versus no direction, $\mathrm{p}<0.001)$. Four of the five dolphins preferred to swim counter-clockwise (Figure 2). At the group level our dolphins also showed a preference to swim counterclockwise ( $t$ test RI, $\mathrm{t}=-3.39, d f=4, \mathrm{p}=0.027$ ).

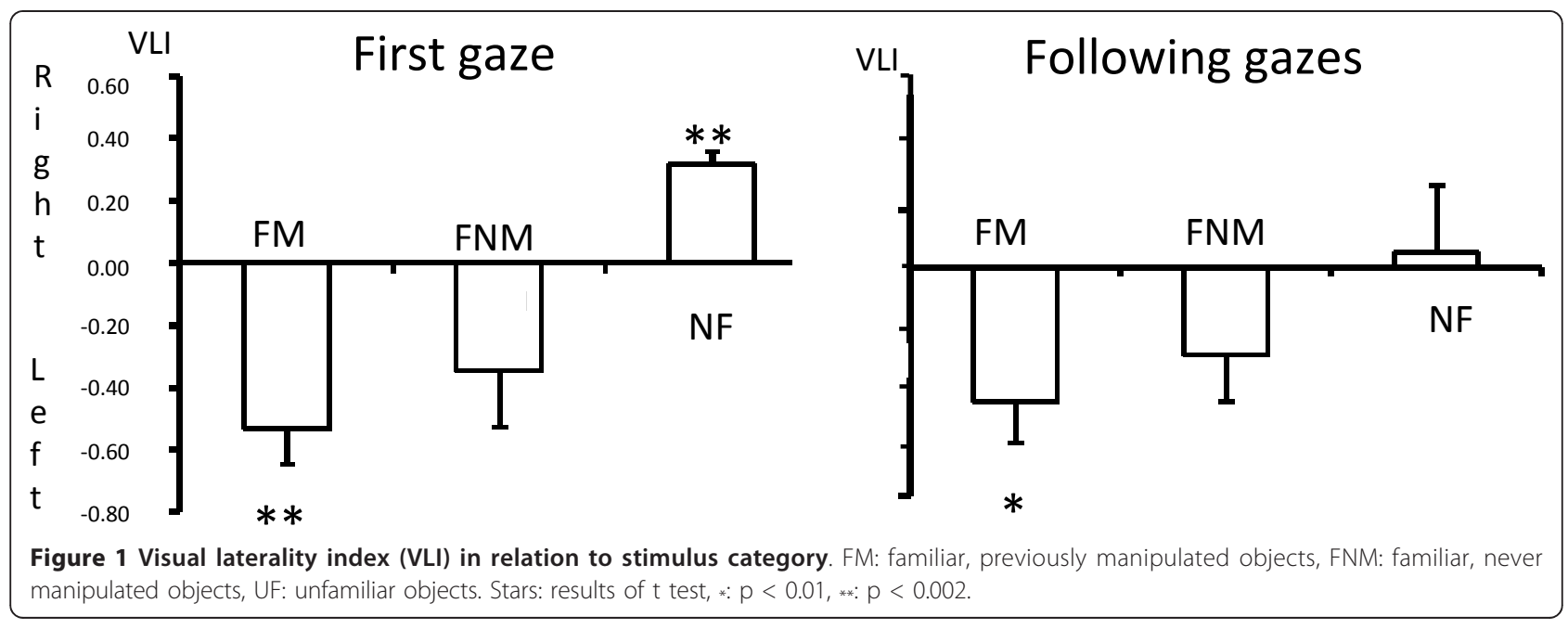


Table 2 Variation of the laterality index (IVL) according the level of object familiarity for the reaction following the first reaction, p: binomial test, bold character: significant results, $p<0.05$, L: left eye used

CECIL PEOS MININOS THEA AMTAN

\begin{tabular}{cccccc}
\hline Familiar-Manipulated & & & & & \\
VLI & -0.28 & $\mathbf{- 0 . 6 1}$ & $\mathbf{- 0 . 6 7}$ & $-\mathbf{0 . 7 8}$ & -0.03 \\
P & 0.132 & $\mathbf{0 . 0 0 0}$ & $\mathbf{0 . 0 0 0}$ & $\mathbf{0 . 0 0 0}$ & 1.000 \\
Bais & ns & $\mathbf{L}$ & $\mathbf{L}$ & $\mathbf{L}$ & ns \\
\hline
\end{tabular}

\begin{tabular}{cccccc}
\hline $\begin{array}{c}\text { Familiars-Never } \\
\text { Manipulés }\end{array}$ & & & & & \\
VLI & $-\mathbf{0 . 4 8}$ & $-\mathbf{0 . 6 0}$ & -0.50 & -0.25 & 0.29 \\
$P$ & $\mathbf{0 . 0 0 3}$ & $\mathbf{0 . 0 3 5}$ & 0.146 & 0.454 & 0.332 \\
Bais & $\mathbf{L}$ & $\mathbf{L}$ & $\mathrm{ns}$ & $\mathrm{ns}$ & $\mathrm{ns}$ \\
\hline Unfamiliar & & & & & \\
VLI & $-\mathbf{0 . 6 9}$ & 0.10 & -0.14 & 0.25 & $\mathbf{0 . 7 3}$ \\
P & $\mathbf{0 . 0 0 0}$ & 0.711 & 0.511 & 0.454 & $\mathbf{0 . 0 0 7}$ \\
Bais & $\mathbf{L}$ & $\mathrm{ns}$ & $\mathrm{ns}$ & $\mathrm{ns}$ & $\mathbf{R}$ \\
\hline
\end{tabular}

\section{Discussion}

Our data showing that all our dolphins used monocular vision spontaneously more frequently than binocular vision confirmed previous reports [26]. This is certainly due to the lateral eye position determining a small binocular visual field in this species. A bias to use their left eye (right hemisphere) to look at very familiar previously manipulated objects emerged clearly at the group level for both the first gaze and the following reactions. The first gaze reaction to unfamiliar objects revealed a preference to use the right eye (left hemisphere). However, this bias disappeared during the subsequent reactions. No eye preference was found for familiar never manipulated objects. Our dolphins also showed a counter-clockwise bias when swimming.

We can first confirm that our dolphins were strongly lateralized when swimming and when looking at objects. The fact that very familiar objects were visually inspected with the left eye while unfamiliar objects were visually

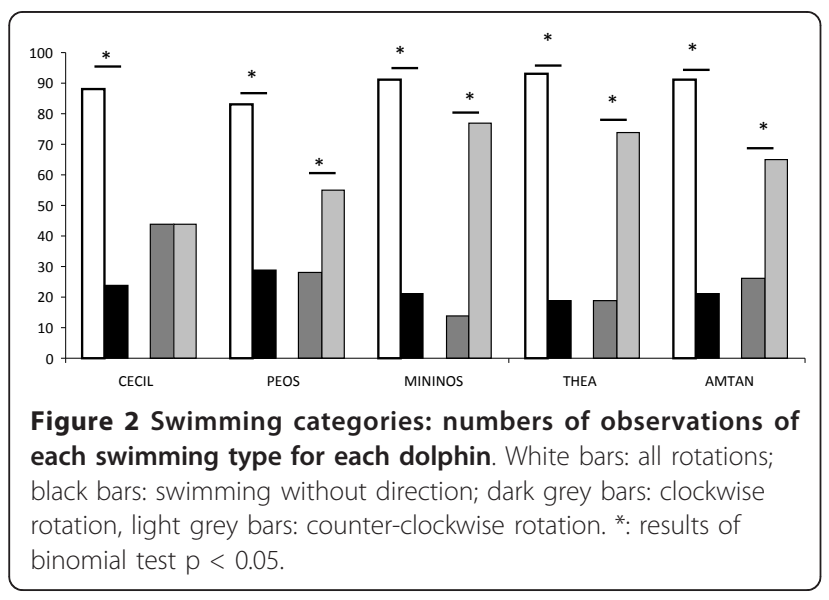

inspected with the right eye, support the first of our three predictions based on the information treatment modality highlighted by Navon $[44,45]$.

This difference of laterality at the group level between previously manipulated stimuli (use of left eye) and unfamiliar stimuli (use of right eye) might thus be explained by the way information leading to identification of objects is treated. During the first inspection of unfamiliar stimuli, dolphins might analyze details of the objects notably to build a spatial mental representation in three dimensions of the different parts of the object. This type of analysis is characteristic of information treatment by the left hemisphere $[46,50,51]$. Conversely, visual analysis of very familiar objects remains global and is characteristic of information treatment by the right hemisphere. Our results confirm the difference between treatments: dolphins used their left eye (right hemisphere) to look at very familiar objects (global analysis) and their right eye (left hemisphere) to look at unfamiliar objects (local analysis). No eye preference was found for the inspection of objects presenting an intermediate familiarity value (familiar non manipulated objects). However, as soon as a previously unfamiliar object has been seen once, this object becomes familiar, but still not manipulated, so no more eye preference is found in the subsequent visual inspections. This change from using the left hemisphere when treating visual information of an unknown shape to using the right hemisphere when that shape has become familiar has been reported previously [48]. The preference to use the right eye to explore details of objects confirm previous reports on the visual discrimination capacities of dolphins [17,26-29]. Dolphins discriminated visually better and solved visio-spatial tasks better using their right eye.

This rapid switch of classes from unfamiliar to familiar support studies that concluded in favor of a rapid visual memorization in dolphins $[52,53]$. The difference of treatment between very familiar and familiar objects also highlights the importance of the manipulation in dolphins. We can suppose that dolphins may possibly have difficulties in constructing a spatial mental representation of familiar never manipulated objects and of unfamiliar objects that have become familiar solely through visual modalities. If this is the case, manipulation of objects by dolphins could facilitate their construction of a global representation of an object enabling dolphins subsequently to categorize it directly, as echolocation and vision are generally linked [53-56].

In a previous study with the same dolphins we found a left-eye preference to look at familiar and unfamiliar human beings [30]. This shows that any human being is treated visually as are very familiar objects, a global inspection being sufficient to have a mental representation of this kind of stimulus. We must acknowledge that 
a human observer was present in this study near the exposed object and that this could have influence the visual response of our dolphins. However, the observer was the same person for all object presentations and always stood at the same place. The fact that the eye used changes with the object category let us think that the presence of the observer had no impact on our data.

In addition to perceptual laterality, we also analyzed swimming laterality and could thus control that the visual laterality observed here was not a direct consequence of swimming preferences. Our dolphins were lateralized at the motor level. Our group revealed a preferred rotation direction (counter-clockwise), thus supporting most previous reports on this theme $[16,24,25]$. This verified our third hypothesis. This rotational bias alone cannot explain the predominance of the use of one eye since the direction of their visual laterality is influenced by stimulus category.

As dolphins are migrant species they are confronted to a changing environment. Being able to categorize new versus familiar objects allows dolphins a best and a rapid adaptation to novel environment. Since we have demonstrated that dolphins used more their left eye to inspect well-known objects (this paper) as well as humans [30], future investigations should explore about the visual preference of dolphins when looking at conspecifics. As dolphins are social species and as other cetacean species, like beluga whale (calves were more on the right side of their mother) [21], expressed social laterality, it will be legitimate to wonder whether dolphins will also use their left eye to look at all kinds of congeners or if the familiarity with the conspecifc has some importance. This social laterality at population level could play an important role in the daily life of species like bottlenose dolphins presenting a fission-fusion social system, i.e. with opportunities to meet conspecifics of different degrees of familiarity.

\section{Conclusion}

We clearly show the influence of a familiarity gradient on dolphins' visual laterality. A bias to use their left eye (right hemisphere) to look at familiar previously manipulated objects emerged clearly at the group level, whereas we found a bias to use the right eye (left hemisphere) to look at unfamiliar objects. A global vs detailed visual treatment can explain the observed laterality.

Swimming laterality was strong but no link was found between visual and swimming laterality. So our experimental results pointed out some cognitive capacities of dolphins that are indispensible for their wildlife [52]. To complete our studies, an analysis of social laterality will be pertinent. On which side a dolphin approach another congener and can the familiarity with the congener modulate this laterality?

\section{Methods}

\section{Subjects}

Our subjects were five captive-born dolphins: three 5 to 25-year old males (Mininos, Peos and Cecil), and two females, respectively 8 and 17 years old (Amtan and Thea). They were housed by the Cité Marine at the Planète Sauvage Safari Park (44, France) in a large aquatic facility (4 pools with 8.5 million liters of water). Six human caretakers fed the dolphins with fish, 6 to 8 times a day, during training and public presentations.

Veterinary assessment of these dolphins' vision revealed no deficiencies and no pathology that might bias our research. The dolphins participated in six training session every day, between 10 o'clock and 16 'clock. They never participated in a public presentation during the course of this study.

\section{Methods}

The dolphins were tested in the round, $20 \mathrm{~m}$ in diameter, $4.85 \mathrm{~m}$ deep maximum, nursery pool. Three types of stimulus were presented: familiar, previously manipulated objects (balls, discs...) (FM), familiar never manipulated objects (diving mask, watering can, boots...) (FNM) and unfamiliar objects (unknown: storage box, kettle, cycle helmet, thermos flask...) (UF). The size range of dolphin's toys varying in size $(0.2 \mathrm{~m}$ to $1 \mathrm{~m})$, as well as in shape and color. Each stimulus was presented once. Twenty objects of each category were used to test the dolphins and each stimulus was presented once.

Before a stimulus was presented, it was hidden behind a curtain so that the dolphins could not see it. The curtain was suspended from a $2 \mathrm{~m}$ high, $1.20 \mathrm{~m}$ wide PVC frame with which the dolphins were already familiar [56]. This curtain was placed $1.20 \mathrm{~m}$ from the pool edge. Behind the curtain the object was placed on a wooden box $(35 \times 40.5 \times 45.5 \mathrm{~cm})$ with which the dolphins were also familiar. This box was used to raise the stimulus making it easier to see (preliminary experiment). The stimuli were presented in air for practical reasons and can be done because dolphins' visual acuteness is globally similar in above and below the water surface [57-59]. Moreover, underwater dolphins might have used not only vision but also echolocation. This frame + box were put in place, two minutes before a test. A trial started when the experimenter opened the curtain. The object remained visible for three minutes. No previous training was necessary, and no reinforcement was given. Dolphins were observed during 180 minutes (20 objects of each category $\times 3$ categories $\times 3$ minutes per object).

During a presentation, all the reactions of the dolphins to the experimental set-up at the surface were recorded, but observations were restricted to the half of the pool close to the objects $(20 \mathrm{~m} \times 9 \mathrm{~m})$ [30]. So our laterality 
study only concentrated on short-distance visual inspection, which means that all dolphins had the chance to first see the object from far before approaching, a still reasonable distance to appreciate whether the object was novel or not. The subjects were filmed in this area of the pool by a video-camera (JVC Everio GZMG332HE) placed on top of the frame [30]. The observer, standing randomly either to the left or to the right of the curtain, described, using a dictaphone (SCOTT DVR 500), all the reactions observed in the area not covered by the camera. The following variables were recorded:

- The identity of the dolphins in the area

- The total number of short gazes at the water surface and the eye with which the subject perceived the stimulus. We first distinguished short and long gazes (i.e. lasting respectively less and more than 2 seconds) (Kuczaj, Pers. Com.). But dolphins performed too few long gazes to possibly include them in the analysis.

At least 15 minutes elapsed after a feeding session, an interaction with careers or a previous test before a test. Three to eight (mean 5.71) tests were made per day and occurred at various time of the day (between $10 \mathrm{~h}$ and $18 \mathrm{~h})$.

\section{MC conducted a blinded analysis of videos}

Independent of experimental tests, the direction of dolphins' spontaneous rotations in the pool was investigated. Hourly instantaneous scan observations between 9.30 o'clock and 16.30 o'clock recorded either rotation direction (clockwise or counter-clockwise) or the absence of rotation for each dolphin. Eight scans were performed per day, yielding 112 scans.

\section{Statistical analyses}

Friedman tests analyzed the numbers of trials when a subject approached the objects of a given category spontaneously in order to look at them and the numbers of gazes at each object. Wilcoxon tests compared use of monocular vision to use of binocular vision.

The first reaction of each dolphin, i.e., the first time a subject observed the object and all the reactions following, the first reaction (= following reactions in the text), were considered separately to estimate laterality. Thus, a visual laterality index (VLI) was calculated for each dolphin using the formula: $(\mathrm{R}-\mathrm{L}) /(\mathrm{R}+\mathrm{L}), \mathrm{R}$ and $\mathrm{L}$ are the numbers of times the right eye and the left eye were used to observe objects. This index varies from -1 to +1 , negative values indicate a preference to use the left eye and positive values a preference to use the right eye. In addition, the absolute value of VLI estimates strength of laterality. Binomial tests evaluated each subject's preference to use one eye by comparing the numbers of times the right eye and the left eye were used for each experimental category. At the population level, $t$ tests, applied to VLI values, estimated the presence of laterality at the group level. Friedman tests on VLI values and on their absolute values evaluated variations of direction and of strength of laterality between experimental conditions. Wilcoxon tests compared direction and strength of laterality between the first reaction and the following reactions.

Finally, binomial tests compared 1) the number of times a subject's swimming presented a lateralized rotation direction to the number of times its swimming presented no precise rotation direction, and 2) the number of times it swam clockwise to the number of times it swam counter-clockwise. A rotation index (RI): (number of times a subject swam clockwise - number of times it swam counter-clockwise)/(total number of rotations) was calculated for each subject. A $t$ test on these RI values estimated the presence of a preferred direction at the group level.

Significance level for all statistical analyses was $\mathrm{p}<$ 0.05 .

Experimental research reported in this manuscript has been performed with the approval of ethics committee (DDSV n 04672).

\section{Acknowledgements}

We thank all caretakers of Planète Sauvage Zoo for technical support, and Ann Cloarec for translation.

\section{Author details}

1UMR 6552 University of Rennes 1 - CNRS, Station Biologique, 35380 Paimpont, France. ${ }^{2}$ Département scientifique, Planète Sauvage, 44710 PortSaint-Père, France.

\section{Authors' contributions}

MC participated in the design of the study, conducted the experiments, and performed the video and statistical analysis. MB participated in the design of the study and conducted the experiment. AL initiated the study, participated in the design of the study and participated in the preparation of the manuscript. $\mathrm{CBH}$ initiated the study, contributed to the design of the study, participated in the statistical analysis, and in the preparation of the manuscript. All authors have read and approved this manuscript.

Received: 12 July 2011 Accepted: 12 January 2012

Published: 12 January 2012

\section{References}

1. Bradshaw JL, Rogers LJ: The Evolution of Lateral Asymmetries, Language, Tool Use, and Intellect San Diego Academic; 1993.

2. Bisazza A, Rogers LJ, Vallortigara G: The Origins of Cerebral Asymmetry: A Review of Evidence of Behavioural and Brain Lateralization in Fishes, Reptiles and Amphibians. Neuroscience and Biobehavioural Reviews 1998, 22:411-426.

3. Byrne RA, Kuba M, Griebel U: Laterally asymmetry of eye use in Octopus vulgaris. Animal Behaviour 2002, 64:461-468.

4. Rogers LJ, Andrew RJ: Comparative vertebrate lateralization Cambridge University Press; 2002.

5. Vallortigara G, Rogers LJ, Bisazza A: Possible evolutionary origins of cognitive brain lateralization. Brain Research Review 1999, 30:164-175. 
6. Vallortigara G: Comparative neuropsychology of the dual brain: A stroll through animals' left and right perceptual worlds. Brain and Language 2000, 73:189-219.

7. Rogers LJ: Evolution of Hemispheric Specialization: Advantages and Disadvantages. Brain and Language 2000, 73:236-253.

8. Hook-Costigan MA, Rogers $\mathrm{L}$ : Eye preferences in common marmosets (Callithrix jacchus): Influence of age, stimulus, and hand preference. Laterality 1998, 3:109-130.

9. Kruper DC, Boyle BE, Patton RA: Eyes and hand preferences in rhesus monkeys (Macaca mulatta). Psychonomic Science 1966, 5:277-278.

10. Hopkins WD, Bennett AJ: Handedness and approach-avoiding behaviour in chimpanzees (Pan). Journal of experimental Psychology: Animal Behaviour Processes 1994, 20:413-418.

11. Rogers $L$, Ward JP, Stanford D: Eye-dominance in the small-eared bushbaby, Otolemur garnettii. Neuropsychologia 1994, 32:257-264.

12. Quaranta A, Siniscalchi M, Vallortigara G: Asymmetric tail-wagging responses by dogs to different emotive stimuli. Current Biology 2007, 17:199-201.

13. Cantalupo C, Bisazza A, Vallortigara G: Lateralization of predator evasion response in a teleost fish (Girardinus falcatus: Poeciliidae). Neuropsychologia 1995, 33:1637-1646.

14. Basile M, Boivin S, Boutin A, Blois-Heulin C, Hausberger M, Lemasson A: Socially dependent auditory laterality in domestic horses (Equus caballus). Animal Cognition 2009, 12:611-619.

15. Bishop PO, Jeremy D, Lance JW: The optic nerve. Properties of a central tract. Journal of Physiology 1953, 121:415-432.

16. Ridgway SH: Physiological observations on the dolphin brain. In Dolphin Cognition and Behavior: A Comparative Approach. Edited by: Schusterman RJ, Thomas JA, Woods FG. Hillsdale NJ, Lawrence Erlbaum; 1986:31-60.

17. Kilian A, Von Fersen L, Güntürkün O: Lateralization of visuospatial processing in bottlenose dolphin (Tursiops truncatus). Behavioural Brain Research 2000, 116:211-215.

18. Tarpley RJ, Ridgway SH: Corpus callosum size in delphinid Cetaceans. Brain Behavior Evolution 1994, 44:156-165.

19. Rogers $L$, Zucca $P$, Vallortigara $G$ : Advantage of having a lateralized brain. Proc Royal Soc London B 2004, S420-S422.

20. Clapham PJ, Leimkuhler E, Gray BK, Mattila DK: Do humpback whales exhibit lateralized behavior? Animal Behaviour 1995, 50:73-82.

21. Karenina K, Giljov A, Baranov V, Osipova1 L, Krasnova V, Malashichev Y: Visual Laterality of Calf-Mother Interactions in Wild Whales. Ploes One 2010, 5:e13787.

22. Stafne GM, Manger PR: Predominance of clockwise swimming during rest in Southern Hemisphere dolphins. Physiology \& Behavior 2004, 82:919-926.

23. Marino L, Stowe J: Lateralized behavior in two captive bottlenose dolphins (Tursiops truncatus). Zoo Biology 1997, 16:173-177.

24. Sakai M, Hishii T, Takeda S, Kohshima S: Laterality of flipper rubbing behavior in wild bottlenose dolphins (Tursiops aduncus): Caused by asymmetry of eye use? Behavioural Brain Research 2006, 170:204-210.

25. Sobel N, Supin AY, Myslobodsky MS: Rotational swimming tendencies in the dolphin (Tursiops truncatus). Behavioural Brain Research 1994, 65:41-45.

26. Delfour F, Marten K: Lateralized visual behavior in bottlenose dolphins (Tursiops truncatus) performing audio-visual tasks: The right visual field advantage. Behavioural Processes 2006, 71:41-50.

27. Kilian $A$, Von Fersen L, Güntürkün O: Left hemispheric advantage for numerical abilities in the bottlenose dolphin. Behavioural Processes 2005, 68:179-184.

28. Von Fersen L, Schall U, Güntürkün O: Visual lateralization of pattern discrimination in the bottlenose dolphin (Tursiops truncatus). Behavioural Brain Research 2000, 107:177-181.

29. Yaman S, von Fersen L, Dehnhardt G, Güntürkün O: Visual lateralization in the bottlenose dolphin (Tursiops truncatus): evidence for a population asymmetry? Behavioural Brain Research 2003, 142:109-114.

30. Thieltges H, Lemasson A, Kuczaj S, Böye M, Blois-Heulin C: Visual laterality in dolphins when looking at (un)familiar humans. Animal Cognition 2011, 14:303-308.

31. Marino L: Dolphin cognition. Current Biology 2004, 14(21):910-911.

32. Huggenberger S: The size and complexity of dolphin brains - a paradox? Journal of the Marine Biological Association of the United Kingdom 2008, 88:1103-1108.

33. Marino L, Sudheimer KD, Murphy TL, Davis KK, Pabst DA, McLellan WA, Rilling JK, Johnson Jl: Anatomy and three-dimensional reconstructions of the brain of a bottlenose dolphin (Tursiops truncatus) from magnetic resonance images. The Anatomical Record 2001, 264:397-414.

34. Morgane PJ, Jacobs MS, Galaburda A: Evolutionary morphology of the dolphin brain. In Dolphin Cognition and Behavior A Comparative Approach. Edited by: Schusterman R, Thomas J, Wood F. Hillsdale NJ, Lawrence Erlbaum; 1986:5-29.

35. Supin A, Mukhametov LM, Ladygina TF, Popov W, Mass AM, Poliakova G: Electro-physiological Investigation of the Dolphin Brain Nauka, Moscow 1978.

36. Dharmaretnam M, Andrew RJ: Age- and stimulus- specific use of right and left eyes by the domestic chick. Animal Behaviour 1994, 48:1395-1406.

37. Mac Kenzie R, Andrew RJ, Jones RB: Lateralization in chicks and hens: new evidence for control of response by the right eye system. Neuropsychologia 1998, 36:51-58.

38. Workman L, Andrew RJ: Asymmetries of eye use in birds. Animal Behaviour 1986, 34:1582-1584

39. Cantalupo C, Bisazza A, Vallortigara G: Lateralization of predator-evasion response in a teleost fish (Girardinus falcatus). Neuropsychologia 1995, 33:1637-1646.

40. Sovrano VA: Visual lateralization in response to familiar or unfamiliar stimuli in fish. Behavioural Brain Research 2004, 152:385-391.

41. Vallortigara G: Right hemisphere advantage for social recognition in the chick. Neuropsychologia 1992, 30:761-768.

42. Hamilton $C R$, Vermeire BA: Complementary Hemispheric Specialization in Monkeys. Sciences 1988, 242:1691-1694.

43. de Boyer des Roches A, Richard-Yris MA, Henry S, Ezzaouïa M, Hausberger M: Laterality and emotions: visual laterality in the domestic horse (Equus caballus) differs with objects' emotional value. Physiology and Behavior 2008, 94:487-490.

44. Navon D: Forest before trees: The Precedence of Global Features in Visual Perception. Cognitive Psychology 1977, 9:353-383.

45. Navon D: Do Attention and Decision Follow Perception? Comment on Miller. Journal of Experimental Psychology: Human Perception and Performance 1981, 7:1175-1182.

46. Kosslyn S, Koenig O, Barrett A, Cave CB, Tang J, Gabrieli JDE: Evidence of two types of spatial representations: hemispheric specialization for categorial and coordinate relations. Journal of Experimental Psychology: Human Perception and Performance 1989, 15:723-735.

47. Delis $D C$, Robertson $L C$, Efron R: Hemispheric specialization of memory for visual hierarchical stimuli. Neuropsychologia 1986, 24:205-214.

48. Laeng B, Shah J, Kosslyn S: Identifying objects unconventional and comforted poses: contributions of hemispheric-specific mechanisms. Cognition 1999, 70:53-85.

49. Farmer K, Krueger K, Byrne RW: Visual laterality in the domestic horse (Equus caballus) interacting with humans. Animal Cognition 2010, 13:229-238.

50. Robertson LC, Lamb MR: Neuropsychological contribution to theories of part/Whole organization. Cognitive Psychology 1991, 299-330.

51. Robertson LC, Lamb MR, Knight RT: Effects of lesions of temporal-Parietal junction on perceptual and attentional processing in humans. The Journal of Neuroscience 1988, 8:3757-3769.

52. Herman LM: What Laboratory Research has Told Us about Dolphin Cognition. International Journal of Comparative Psychology 2010, 23:310-330.

53. Herman LM, Pack AA, Hoffmann-Kuhnt M: Seeing through sound: dolphins perceive the spatial structure of objects through echolocation. Journal of Comparative Psychology 1998, 112:292-305.

54. Harley HE, Roitblat HL, Nachtigall PE: Object representation in the bottlenose dolphin (Tursiops truncatus): integration of visual and echoic information. Animal Behavior Processes 1996, 22(2):164-174.

55. Pack AA, Herman LM: Sensory integration in the bottlenosed dolphin: Immediate recognition of complex shapes across the senses of echolocation and vision. Journal of the Acoustical Society of America 1995 98:722-733.

56. Pack AA, Herman LM, Hoffmann-Khunt M, Branstetter BK: The object behind the echo: dolphins (Tursiops truncatus) perceive object shape globally through echolocation. Behavioural Processes 2002, 58:1-26.

57. Herman LM, Peacock MF, Yunker MP, Madsen CJ: Bottlenose dolphin: double-slit pupil yields equivalent aerial and underwater diurnal acuity. Science 1975, 189:651-652.

58. Rivamonte LA: Eye model to account for comparable aerial and underwater acuities of the bottlenose dolphin. Netherlands Journal of Sea Research 1976, 10:491-498. 
59. Rivamonte LA: Bottlenose dolphin (Tursiops truncatus) double-slit pupil asymmetries enhance vision. Aquatic Mammals 2009, 35:269-280.

doi:10.1186/1471-2202-13-9

Cite this article as: Blois-Heulin et al: Visual laterality in dolphins:

importance of the familiarity of stimuli. BMC Neuroscience 2012 13:9.

Submit your next manuscript to BioMed Central and take full advantage of:

- Convenient online submission

- Thorough peer review

- No space constraints or color figure charges

- Immediate publication on acceptance

- Inclusion in PubMed, CAS, Scopus and Google Scholar

- Research which is freely available for redistribution

Submit your manuscript at 